\title{
Early life undernutrition in rats
}

\author{
3. Motor performance in adulthood \\ BY J. L. SMART AND K. S. BEDI* \\ Department of Child Health, University of Manchester, The Medical School, \\ Oxford Road, Manchester MI3 9PT
}

\section{(Received 7 September 1981 - Accepted 26 November 1981)}

\begin{abstract}
1. A detailed investigation was made of the motor performance of rats which had impaired cerebellar and muscular growth resulting from early-life undernutrition.

2. Developing rats were growth-retarded by underfeeding their mothers during pregnancy and lactation. They were fed ad lib. from $25 \mathrm{~d}$ of age.

3. Adult male previously-undernourished (PU) and well-fed control rats were given tests of motor behaviour commencing at 5 months of age. They were required to run backwards to maintain their position on a revolving drum. Aspects of the test situation were varied systematically: visual environment, interval between trials, test duration and drum speed.

4. PU rats had a $29 \%$ body-weight deficit compared with controls at 5 months.

5. There was no evidence of impaired motor performance by the PU rats under any of the test conditions.
\end{abstract}

Undernutrition at the time of the brain growth spurt is known to result in lasting deficits in the weight and cellularity of the brain. Furthermore, there is a selective effect on the cerebellum, such that it is disproportionately small in relation to the rest of the brain (Culley \& Lineberger, 1968; Chase et al. 1969; Adlard et al. 1973). This finding of especial cerebellar vulnerability, coupled with the knowledge that the cerebellum is involved in the coordination of movement, led to the formulation of the hypothesis that early-life undernutrition might result in impairment of motor co-ordination.

The results of the several experiments which have been carried out to test the hypothesis are equivocal. Previously-undernourished rats (PU) fell more frequently than well-fed controls (C) off a revolving drum when required to run backwards to maintain their position on it (Lynch et al. 1975; Jordan et al. 1979), and they also missed their footing more frequently while negotiating a chasm bridged by two parallel rods (Lynch et al. 1975). However, there have been several studies with rats in which no impairment of motor performance was found (Guthrie, 1968; Slob et al. 1973; Galler \& Turkewitz, 1977).

The reason for the equivocal nature of the findings is obscure. One possibility is that the exact nature of the test and the way in which it is conducted may be important, and that impaired performance is revealed only under particular circumstances. Experience in our laboratory provides a specific hypothesis. In recent tests of motor ability, using the same strain of rat and the same apparatus as we employed previously (Lynch et al. 1975), I have not been able to confirm that the performance of PU rats is impaired (Smart, Unpublished results). One notable difference between these studies was in the visual properties of the rooms in which the tests were performed: previously in a room providing highly-structured visual input, and recently in a relatively featureless room. Also the principal difference between studies in the behaviour of the animals was that the $\mathrm{C}$ rats performed much worse in the recent study than they had in the earlier one. These factors together suggest that performance may be facilitated if there is a structured visual environment in the vicinity of the test apparatus: specifically, the rats may find it easier to maintain their position if they fixate on some stationary object.

- Present address: Department of Anatomy, University of Aberdeen, Marischal College, Aberdeen AB9 1AS. 
In the present investigation rats which had been undernourished during gestation and the suckling period were tested as adults for their ability to run backwards on a revolving drum. To test for the importance of the visual environment, half the animals in one experiment were run with structured visual input from the wall facing them as they ran on the drum, and half with the wall bare. Another factor which is quite likely to have differed between investigations is the interval between trials on the drum. This was systematically varied in a second experiment. All rats were retested 2 weeks after their initial test in an attempt to replicate the finding of Jordan et al. (1979) that $C$ rats benefit much more in terms of performance from their initial experience of running on the drum than do PU rats. To investigate the possibility of differences in susceptibility to fatigue, rats were run for an extended period. Finally, in a third test, they were run at a higher drum speed.

\section{METHODS}

Developing rats were undernourished during gestation and the suckling period by underfeeding their mothers as described by Bedi et al. (1982). They were given a good-quality diet ad lib. from $25 \mathrm{~d}$. Only male rats were given tests of motor behaviour and these commenced at 5 months of age.

The apparatus and the conduct of the tests were as described by Smart et al. (1973) with the exception of the following modifications. The structure of the drum was altered to make it more difficult for the rats to turn round. The diameter remained $150 \mathrm{~mm}$, but the width of the running surface was reduced to $90 \mathrm{~mm}$ and the height of the walls bounding the running surface was increased to $180 \mathrm{~mm}$. The fall from the drum was $930 \mathrm{~mm}$ on to a thick foam-rubber surface.

Rats were tested in white light, but during the red phase of their red light-white light cycle. They were removed from red light, given $10 \mathrm{~min}$ to accommodate to white light, and were then placed on top of the stationary drum where they remained for $1 \mathrm{~min}$ before the drum was switched on. The rats were required to run backwards to maintain their position on the drum. For tests 1 and 2 the drum speed was $10 \mathrm{rev} / \mathrm{min}$.

\section{Test 1}

Four male littermates were used from each of $8 \mathrm{C}$ and $8 \mathrm{PU}$ litters. These were distributed equally between two separate experiments, $\mathrm{A}$ and $\mathrm{B}$. In both experiments the number of falls from the drum in a total of 3 min running time was recorded.

Test $1 \mathrm{~A}$ was conducted to investigate the importance of the visual environment to the test performance. For eight $\mathrm{C}$ and eight PU rats a visual-stimulus sheet was attached to the wall facing the animal on the drum. On the $840 \times 460 \mathrm{~mm}$ rectangular sheet was a criss-cross pattern of 20 and $50 \mathrm{~mm}$ wide lines of three different shades making right-angle intersections with one another. The centre of the sheet was $1000 \mathrm{~mm}$ from the top surface of the drum. The other eight $\mathrm{C}$ and eight PU rats were tested with the uniformly-painted wall bare.

In test $1 \mathrm{~B}$ the interval between trials was varied. Eight $\mathrm{C}$ and eight $\mathrm{PU}$ animals were tested with the minimum interval between trials: that is, they were replaced on the drum as soon as conveniently possible after falling off (in practice, after approximately $12 \mathrm{~s}$ ). The remaining eight $\mathrm{C}$ and eight $\mathrm{PU}$ rats were allowed an additional period of $15 \mathrm{~s}$ before being replaced on the drum. The plain wall situation was used.

\section{Test 2}

Two weeks after test 1 all animals (test $1 \mathrm{~A}$ and test $1 \mathrm{~B}$ ) were tested again. All were given 10 min running time on the drum in the plain wall situation with the minimum interval between trials. 
Table 1. Body-weights $(\mathrm{g})$ of well-fed control $(C)$ and previously-undernourished $(P U)$ male rats at birth, 25 and $154 \mathrm{~d}$

(Mean values with their standard errors; no. of litters in parentheses)

\begin{tabular}{|c|c|c|c|c|c|}
\hline & \multicolumn{2}{|c|}{$C(8)$} & \multicolumn{2}{|c|}{ PU (8) } & \multirow{2}{*}{$\begin{array}{c}\text { Statistical } \\
\text { significance } \\
\text { of difference } \\
\text { between } \\
\text { groups*: } P\end{array}$} \\
\hline & Mean & $\mathrm{SE}$ & Mean & $\mathbf{S E}$ & \\
\hline \multicolumn{6}{|c|}{ Body-wts (g) at: } \\
\hline Birth & $5 \cdot 61$ & 0.09 & $5 \cdot 18$ & 0.14 & $<0.02$ \\
\hline $25 \mathrm{~d}$ & $55 \cdot 37$ & 1.21 & $16 \cdot 35$ & 1.38 & $<0.001$ \\
\hline $154 \mathrm{~d}$ & $432 \cdot 01$ & $10 \cdot 71$ & $308 \cdot 61$ & $10 \cdot 61$ & $<0.001$ \\
\hline
\end{tabular}

* Student's $t$ test.

Test 3

A further 2 weeks later all rats were run for $2 \mathrm{~min}$ at the higher speed of $13 \mathrm{rev} / \mathrm{min}$. Other conditions were as in Test 2.

RESULTS

Body-weight

Body-weights of $\mathrm{C}$ and PU rats at birth, at the end of the period of underfeeding ( $25 \mathrm{~d}$ ) and 22 weeks are shown in Table 1 . Underfed rats had weight deficits of $8 \%$ at birth and $70 \%$ at $25 \mathrm{~d}$. After 18 weeks of ad lib feeding their relative weight deficit had diminished to $29 \%$, though their deficit in absolute weight had increased more than threefold, from 39 to $123 \mathrm{~g}$.

\section{Behaviour}

The number of falls from the revolving drum during the first, second and third minutes of test 1 and the total of these were each subjected to two-way analysis of variance (nutritional treatment $x$ test condition: non-parametric analysis of variance, Scheirer et al. 1976). In neither test $1 \mathrm{~A}$ nor test $1 \mathrm{~B}$ was there a significant effect of nutritional treatment or test condition nor was the interaction component of variance significant. That is, additional visual input had no effect in test $1 \mathrm{~A}$ and the increased interval between trials had no influence in test $1 \mathrm{~B}$ (Fig. 1). The exclusion of the two control rats, which did not learn to run backwards on the drum throughout the $3 \mathrm{~min}$, from the analysis of the test $1 \mathrm{~A}$ results did not alter the previous conclusions in any way. These animals were not tested further.

Analysis of the results of tests 2 and 3 was performed on the mean values for each litter rather than on individual values, according to the recommendation of Abbey \& Howard (1973). This has the effect of reducing the values for $n$ to eight for both the C and PU groups. There is no evidence that the PU rats were more fatigued than their controls in either the first or second 5 min of test 2 (Mann-Whitney $U$ test). If anything, they fell less frequently especially in the latter half of the test (Fig. 2).

During test 3 , in which the drum speed was increased to $13 \mathrm{rev} / \mathrm{min}$, five rats (two $\mathrm{C}$ and three PU) gave up trying to maintain their position on the drum. Their testing was terminated when this became clear and their results are excluded from the analysis. PU rats tended to fall less frequently than $\mathrm{C}$ animals in test $3(P=0.064$, Mann-Whitney $\mathrm{U}$ test, two-tailed), especially during the second minute (Fig. 2). 


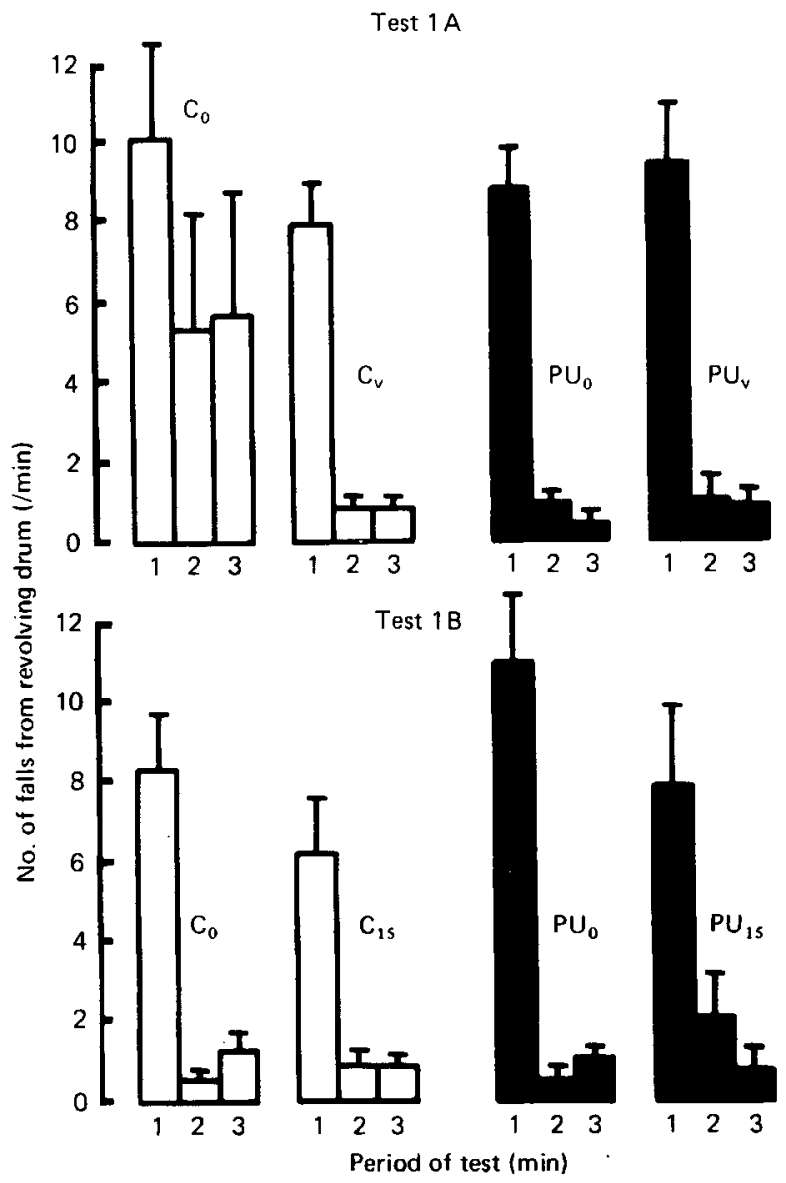

Fig. 1. Test 1. Mean falls from the revolving drum by control $(\square ; C)$ and previously-undernourished ( $\mathbf{D}$; PU) rats in tests $1 \mathrm{~A}$ and $1 \mathrm{~B}$. In test $1 \mathrm{~A}$ visual input in the test situation was either plain $\left(\mathrm{C}_{0}, \mathrm{PU}_{0}\right)$ or structured $\left(\mathrm{C}_{\mathrm{v}}, \mathrm{PU}_{\mathrm{v}}\right)$. In test $1 \mathrm{~B}$ the interval between trials was either minimal $\left(\mathrm{C}_{0}, \mathrm{PU}_{0}\right)$ or longer by $15 \mathrm{~s}\left(\mathrm{C}_{15}, \mathrm{PU}_{15}\right)$. Vertical bars represent standard errors. For details of tests, see p. 440 .

Test 2
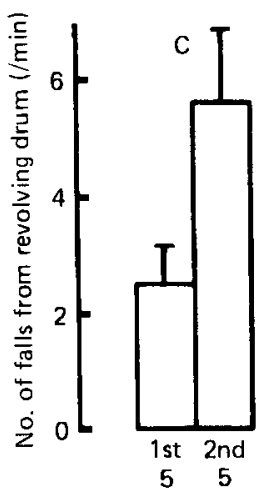

PU

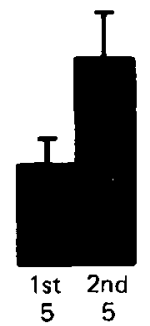

Test 3

C

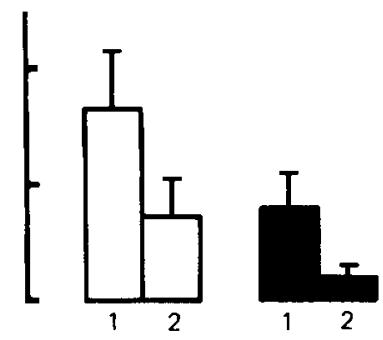

Period of test ( $\mathrm{min}$ )

Fig. 2. Tests 2 and 3. Mean falls from the revolving drum by control $(\square ; C)$ and previouslyundernourished ( $\square$; PU) rats. Drum speed was $10 \mathrm{rev} / \mathrm{min}$ in test 2 and $13 \mathrm{rev} / \mathrm{min}$ in test 3 . Vertical bars represent standard errors. For details of tests, see p. 440. 


\section{DISCUSSION}

There was no evidence from the present investigation of any impairment in the performance of revolving drum tests by PU rats. This was so in all the test conditions, and hence there is no support for the suggestion that contradictory results from previous studies resulted from differences in the visual properties of the test situation or in the interval between trials on the drum.

It is probably appropriate to question whether the revolving drum provides a good test of motor co-ordination and, indeed, whether it tests co-ordination ability at all. The apparatus used in the present investigation and by Lynch $e$ t al. (1975) was a modification of that developed by Seamer \& Peto (1969) to test for the effects of viral encephalomyelitis in mice. They found only slight impairment in the performance of infected mice and comment on wide variations between individual mice and between batches of mice. The clearest indication of the effectiveness of the test in revealing impairments in motor ability appears to come from experiments on effects of X-irradiation to the brain in infancy (Lynch et al. 1976). X-irradiation, at the dose level applied, destroys dividing cells. The earlier the irradiation within the period studied (6-12 d) the greater the effect on adult brain weight, especially cerebellar weight, and on performance on the revolving drum. That is, there was good correspondence between the effects on brain and behaviour. Further experiments indicated strongly that the cerebellar deficit caused the impairment in performance on the revolving drum. Hence the test would appear to be sufficiently sensitive to reveal certain deficiencies in motor function.

It ought to be pointed out that motor function, as measured in this test, is not an isolated characteristic divorced from all others, but may be subject to influence by such factors as learning and motivation. Learning is certainly a major component of performance on the revolving drum, as shown by the decline in number of falls from the first to the second minute of testing (Fig. 1). Direct observation indicates that the transition from falling frequently to falling seldom is usually quite abrupt. The animals seem to 'catch on' to what is required of them. Obviously, any differences between groups in learning ability could either exaggerate or obscure differences in motor co-ordination, depending on their direction. The same is true of differences in motivation. Hence a negative result from the revolving drum test does not completely rule out the possibility of impaired co-ordination.

Inspection of the published literature on early undernutrition and motor ability suggests that the timing or duration of nutritional deprivation may be important. In the studies which obtained positive results undernutrition was imposed during gestation and the suckling period (Lynch et al. 1975; Jordan et al. 1979), but underfeeding commenced only at birth in those finding no effect (Guthrie, 1968; Slob et al. 1973; Galler \& Turkewitz, 1977), thus apparently implicating gestation or gestation combined with the suckling period as the vulnerable period. Duration of deprivation is, of course, a confounding factor in this analysis, but it does not appear to be a crucial factor since one of Guthrie's (1968) groups was malnourished for as long as 9 weeks and still performed normally. Unfortunately, the results of the present investigation, in which mother rats were underfed from the day after mating, lend no support whatsoever to this hypothesis of gestational vulnerability.

It is perhaps worth entertaining the idea that the brain deficits resulting from early treatment may have to exceed a threshold value before effects on behaviour become apparent. Quantitative evidence from two X-irradiation studies appears to support this view with respect to cerebellar weight deficits and motor ability. Altman et al. (1971) found negligible effects on the development of motor ability of irradiation treatment in infancy producing a $26 \%$ cerebellar weight deficit, but marked effects of treatment causing a $46 \%$ deficit. Similarly, Lynch et al. (1976) obtained normal performance on the revolving drum 
in rats with $29 \%$ cerebellar deficits, but impaired performance when the deficit was $40 \%$. The simple conclusion from these studies, that only cerebellar weight deficits of the order of $40 \%$ or more are associated with deficient motor ability, if applied to undernutrition research, suggests that it is highly unlikely that early undernutrition would have any lasting effect on motor ability since cerebellar deficits hardly ever exceed $30 \%$ in PU animals. For example, PU rats have been found to have cerebellar weight deficits of 16,13 and $26 \%$ (Lynch et al. 1975; Jordan \& Howells, 1978; Bedi et al. 1982). However, such extrapolation from irradiation to nutritional studies is hazardous because of the differences in the nature and timing of the treatments and it is probably prudent to eschew any direct comparison of results. The threshold idea may still be useful, but perhaps in relation to some as yet unspecified component of structure rather than to such a crude measure as weight of whole cerebellum.

Jordan et al. (1979) found performance on a revolving drum to be impaired in rats which were undernourished and tested in similar fashion to those in the present investigation, and suggest that a greater susceptibility to fatigue may have contributed to the PU rats' poor performance in their 3 min test. The results of the considerably longer, $10 \mathrm{~min}$ test in the present investigation, in which PU rats tended to fall less often from the drum especially in the latter part of the test, indicate that this suggestion is highly unlikely. Furthermore, the findings from the investigation of muscle physiology support this conclusion (Wareham et al. 1982). Whole muscles from PU and $\mathrm{C}$ rats did not differ significantly in their strength of contraction, despite the $23-25 \%$ deficit in the weight of muscles from PU animals, and when strength of contraction was expressed against wet weight of muscle the values for PU rats tended to exceed those for their controls. Indeed, there is no indication from the present investigations of any deficiency resulting from early undernutrition in either the physiological characteristics of muscle or in whole animal motor function.

This research was funded from grants to Professor John Dobbing by the Medical Research Council and the National Fund for Research into Crippling Diseases. The authors are grateful to Drs Mike Mahon (Anatomy Dept) and Tony Wareham (Physiology Dept) for helpful discussions during the preparation of the manuscript.

\section{REFERENCES}

Abbey, H. \& Howard, E. (1973). Devl Psychobiol. 6, 329.

Adlard, B. P. F., Dobbing, J. \& Smart, J. L. (1973). Biol. Neonate 23, 95.

Altman, J., Anderson, W. J. \& Strop, M. (1971). Physiol. Behav. 7, 143.

Bedi, K. S., Birzgalis, A. R., Mahon, M., Smart, J. L. \& Wareham, A. C. (1982). Br. J. Nutr. $47,417$.

Chase, H. P., Lindsley, W. F. B. \& O'Brien, D. (1969). Nature, Lond. 221, 554.

Culley, W. J. \& Lineberger, R. O. (1968). J. Nutr. 96, 375.

Galler, J. R. \& Turkewitz, G. (1977). Physiol. Behav. 19, 697.

Guthrie, H. A. (1968). Physiol. Behav. 3, 619.

Jordan, T. C. \& Howells, K. F. (1978). Brain Res. 157, 202.

Jordan, T. C., Howells, K. F. \& Piggott, S. M. (1979). Behav. Neurol Biol. 25, 126.

Lynch, A., Dobbing, J., Adlard, B.P. F. \& Smart, J. L. (1976). Biol. Neonate 28, 140.

Lynch, A., Smart, J. L. \& Dobbing, J. (1975). Brain Res. 83, 249.

Scheirer, C. J., Ray, W. S. \& Hare, N. (1976). Biometrics 32, 429.

Seamer, J. \& Peto, S. (1969). Lab. Anim. 3, 129.

Slob, A. K., Snow, C. E. \& de Natris-Mathot, E. (1973). Devl Psychobiol. 6, 177.

Smart, J. L., Dobbing, J., Adlard, B. P. F., Lynch, A. \& Sands, J. (1973). J. Nutr. 103, 1327.

Wareham, A. C., Mahon, M., Bedi, K. S. \& Smart, J. L. (1982). Br. J. Nutr. 47, 433. 